\title{
STUDY ON FRONT-END BIDIRECTIONAL DC/DC CONVERTER OF PHOTOVOLTAIC GRID-CONNECTED INVERTER
}

\author{
Guangping Lu1, Lanhong Zhang ${ }^{2}$, Yingchun Bu 3 , Yunlong Zhou ${ }^{4}$ \\ ${ }^{1,2,4}$ School of Electrical Engineering of Yancheng Institute of \\ Technology, Jiangsu 224051 China \\ ${ }^{3}$ Infrastructure Construction Department of Yancheng Institute of \\ Technology, Jiangsu 224051 China \\ email:luguangp@hotmail.com
}

\begin{abstract}
With the development of science and technology, virtual reality technology as a new technology has been applied to more and more areas. In the traditional shipbuilding industry, the shipbuilding period is usually long and frontline workers tend to make mistakes because of negligence of small details while making ship fitting according to the two - dimensional drawing of the ocean designer. In this study, virtual reality technology is applied to build a three - dimensional solid model in order to realize a vivid expression of the ship model and its assembly process. Compared with the traditional abstract drawing, the three-dimensional solid model allows designers and shipbuilders to be more unified, avoids wasting of resources in the construction process and makes it more convenient for the frontline workers to operate in reality, so as to improve the shipbuilding efficiency and shorten the shipbuilding cycle.
\end{abstract}

Keywords: Photovoltaic grid-connected inverter, Bi-direction, Direct current/direct current converter.

\section{Introduction}

With the all-round development of social economy, demands on energy become larger and larger. The development and application of green renewable energy has become an important approach for satisfying the demand of human being on energy [1]. Prof. Gheorghe [2] thought that challenges faced by the energy field were changeable and proposed strategies for controlling no power in photovoltaic parks and regulating national energy system capacity through inducing no power/capacitive power.

Tunlasakun $T$ [3] put forward digital signal processing (DSP) based islanding protection for the underfrequency/ overfrequency and undervoltage/overvoltage of grid-connected inverter. He found that the prototype could close the relay between grid-connected inverter and public electric network when the frequency was higher than $48 \mathrm{~Hz}$ or $52 \mathrm{~Hz}$ and the voltage was lower than $200 \mathrm{~V}$ or $240 \mathrm{~V}$. Grid-connected inverter as one hotspot in the research concerning energy renewability can be typed into single stage type and double stage type according to structures [4]. Photovoltaic grid-connected inverter is an important appliance for solar energy. Direct current/direct current (DC/DC) convertor is the topological structure of switching converters and also an important component of photovoltaic gridconnected inverters [5].

A photovoltaic grid-connected inverter increases or decreases the input voltage through conversion using DC/DC converter and realizes power maximization through regulating output. It can be considered that, the main function of DC/DC converter is to adjust uncontrollable direct voltage to controllable direct voltage [6,7]. DC/DC converter mainly includes unidirectional converter and bidirectional converter [8]. Generally, bidirectional DC/DC converter has larger research value and actual effect in practice [9]. Theoretically, bidirectional flow of energy can be realized by replacing the unidirectional switch and diode of unidirectional DC/DC converter into bidirectional switch using reasonable controlling method [10].

The topology of bidirectional DC/DC converter can be typed into isolated form and non-isolated form [11]. The current bidirectional DC/DC converter is featured by small volume, low weight, low price and good electrical property [12].

This study analyzed circuit topology and rules of bidirectional DC/DC converter and made a design based on it to realize systemic structure and DSP based control. The simulation results demonstrated the design was correct and feasible. 


\section{Grid-connected Photovoltaic Power Generation System}

\subsection{Introduction of grid-connected photovoltaic power generation system}

Studies on photovoltaic grid-connected system started from the 1950s and 1960s. Photovoltaic gridconnected system is a subsystem of photovoltaic power generation system [13]. Since the 21 century, photovoltaic grid-connected power generation technology has been promoted in more and more countries. Grid-connected power generation system is used to invert electronics stored in solar photovoltaic cell and send it to load through power grid [14].
The typical structure of photovoltaic gridconnected system is composed of photovoltaic array, DC-DC converter, direct current-alternating current (DC-AC) converter and sampling protection device, as shown in figure 1. Photovoltaic grid-connected inverter can be typed into isolated photovoltaic inverter and non-isolated photovoltaic inverter. Isolated photovoltaic inverter can be typed into high-frequency isolated photovoltaic inverter and power frequency isolated photovoltaic inverter [15]. Compared to high-frequency isolated photovoltaic inverter, power frequency isolated photovoltaic inverter featured by stable performance and simple structure is used more frequently currently. But it also has defects such as large volume and low efficiency [16].

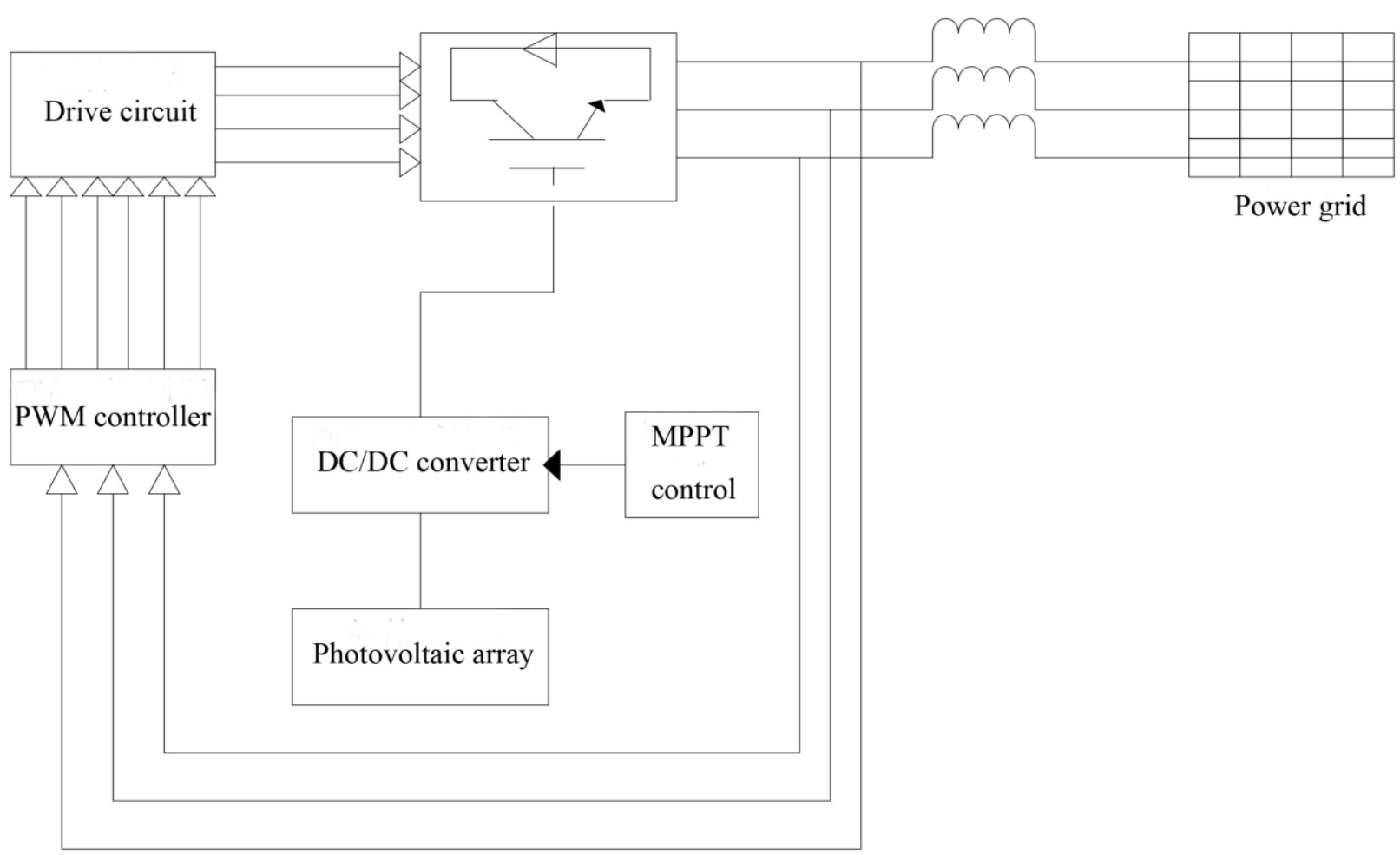

Figure 1: The structure of photovoltaic grid-connected system

\subsection{Solar cell}

With the changes of weather, sunlight strength and air temperature, the output power of solar photovoltaic cell will also change [17]. To keep the output of photovoltaic cell at the maximum value, corresponding controlling method was adopted.

Solar cell is a voltage source which can automatically transform into current source when it works with light energy. The circuit of solar cell is shown in figure 2 .

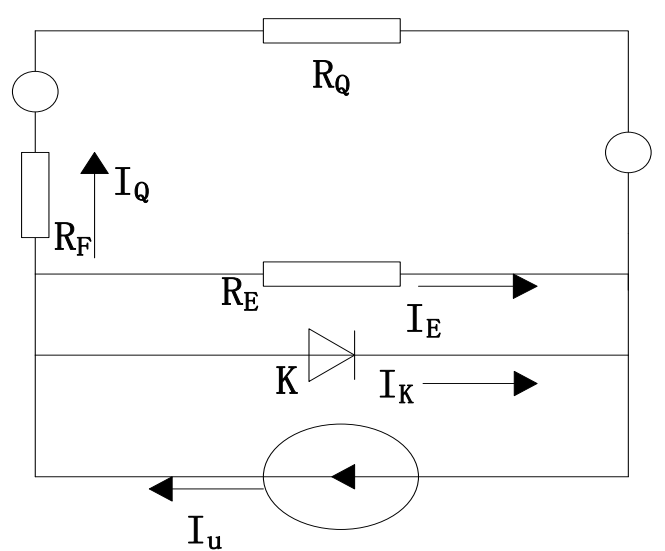

Figure 2: The circuit of a solar cell 
In the figure, RF refers to cascade equivalent resistance, $\mathrm{RE}$ refers to parallel resistance, and $\mathrm{RQ}$ refers to the load of the cell. An ideal solar cell is with relatively small RF and relatively large RE.

\section{Topology of Bidirectional DC/DC converter and its Modeling}

\subsection{Topology of bidirectional DC/DC converter}

The common bidirectional DC/DC converter topology includes bidirectional Buck-Boost, Flyback, Push-Pull, etc [18]. As to isolated converter, compound transformer is difficult to be designed, because current is large when low voltage is input and more turns of primary side are needed when high voltage is input. But non-isolated bidirectional Buck-Boost converter can transform energy at the highest power. In this study, non-isolated converter was selected because isolation was not needed.

Figure 1 demonstrates the operation rules of Buck-Boost converter. Bidirectional Buck-Boost converter is a commonly used non-isolated bidirectional DC/DC circuit.

As shown in figure 3, L1 and L2 are fullycontrolled switches. In forward work, L2 is in a closed state and Pulse-width modulation (PWM) control is performed on L1. D2, the diode of S2, is responsible for follow current, i.e., energy flow from top to bottom, when S1 is closed. In this stage, the circuit is in the Buck working state and the accumulator is charged by the bus. When L1 is closed, the circuit is in the boost state and the energy returns to the bus from the accumulator. The connectivity of L1 and L2 at the same time is impossible for bidirectional Buck-Boost converter.

The topological structure of bidirectional BuckBoost converter is shown in figure 2 . The position of inductor Q and L1 was exchanged. When L1 is closed, PWM control is performed on L2, the circuit is in the boost mode, and energy returns from the accumulator to the bus; when L2 is closed, the circuit is in the Buck mode and the accumulator is charged by the bus. When L1 and L2 are connected at the same time, the working mode of the converter turns to be alternation.
The topology is usually used in the switching power supply of bidirectional DC/DC converter.

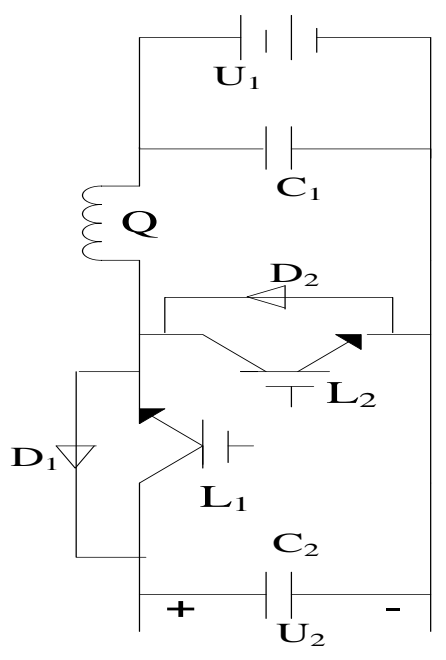

Figure 3: Schematic diagram of bidirectional BuckBoost converter

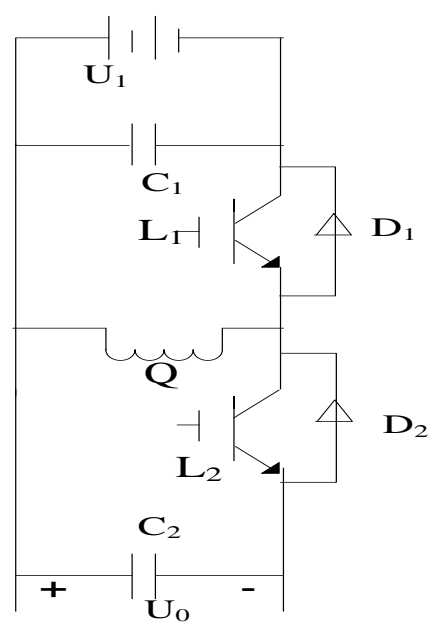

Figure 4: Topology of bidirectional Buck-Boost converter

$$
\dot{x}=F(\mathrm{x}, \mathrm{a}, s)
$$

was used to represent the state equation of the circuit. The working point of the circuit was supposed as , then the Taylor's series of formula (1) was:

$$
\begin{aligned}
& \dot{x}=F\left(x_{0}, a_{0}, s_{0}\right)+\frac{\partial F\left(x_{0}, a_{0}, s_{0}\right)}{\partial x}\left(x-x_{0}\right)+\frac{\partial F\left(x_{0}, a_{0}, s_{0}\right)}{\partial a}\left(a-a_{0}\right)+\frac{\partial F\left(x_{0}, a_{0}, s_{0}\right)}{\partial s}\left(s-s_{0}\right) \\
& +R\left(x-x_{0}\right)+R\left(a-a_{0}\right)+R\left(s-s_{0}\right) \\
& \text { As } \dot{x}=F(\mathrm{x}, \mathrm{a}, s), \text { thus we have: }
\end{aligned}
$$




$$
\begin{aligned}
& \dot{x}-\dot{x}_{0}=\frac{\partial F\left(x_{0}, a_{0}, s_{0}\right)}{\partial x}\left(x-x_{0}\right)+\frac{\partial F\left(x_{0}, a_{0}, s_{0}\right)}{\partial a}\left(a-a_{0}\right)+\frac{\partial F\left(x_{0}, a_{0}, s_{0}\right)}{\partial s}\left(s-s_{0}\right) \\
& +R\left(x-x_{0}\right)+R\left(a-a_{0}\right)+R\left(s-s_{0}\right)
\end{aligned}
$$

Thereinto

$$
\begin{gathered}
\frac{\partial F}{\partial x}=\left[\begin{array}{llll}
\frac{\partial F_{1}}{\partial x_{1}} & \frac{\partial F_{1}}{\partial x_{2}} & \ldots & \frac{\partial F_{1}}{\partial x_{m}} \\
\frac{\partial F_{2}}{\partial x_{1}} & \frac{\partial F_{2}}{\partial x_{2}} & \ldots & \frac{\partial F_{2}}{\partial x_{m}} \\
\frac{\partial F_{n}}{\partial x_{1}} & \frac{\partial F_{n}}{\partial x_{2}} & \ldots & \frac{\partial F_{n}}{\partial x_{m}}
\end{array}\right] \\
F=\left[\begin{array}{c}
F_{1} \\
F_{2} \\
\cdots \\
F_{n}
\end{array}\right] x=\left[\begin{array}{l}
x_{1} \\
x_{2} \\
\cdots \\
x_{m}
\end{array}\right]
\end{gathered}
$$

When $\mathrm{m}=\mathrm{n}$, suppose $\hat{x}=x-x_{0}, \hat{a}=a-a_{0}$ and $\hat{s}=s-s_{0}$ we have:

$\dot{\hat{x}}=\frac{\partial F\left(x_{0}, a_{0}, s_{0}\right)}{\partial x} \hat{x}+\frac{\partial F\left(x_{0}, a_{0}, s_{0}\right)}{\partial a} \hat{a}+\frac{\partial F\left(x_{0}, a_{0}, s_{0}\right)}{\partial s} \hat{s}$

Let

$$
\begin{aligned}
& \frac{\partial F\left(x_{0}, a_{0}, s_{0}\right)}{\partial x}=\mathrm{A}, \frac{\partial F\left(x_{0}, a_{0}, s_{0}\right)}{\partial a}=\mathrm{B}, \\
& \frac{\partial F\left(x_{0}, a_{0}, s_{0}\right)}{\partial s}=\mathrm{C}, \text { then we got the following }
\end{aligned}
$$
model:

$$
\begin{aligned}
& \hat{x}=\mathrm{A} \hat{x}+\mathrm{B} \hat{a}+\mathrm{C} \hat{s} \\
& \text { where: } \quad x=\left[\begin{array}{l}
u_{q} \\
p_{\beta}
\end{array}\right] \mathrm{a}=\left[a_{u}\right]
\end{aligned}
$$

$\mathrm{x}$ stands for input vector, a stands for output vector, $\mathrm{u}_{\mathrm{q}}$ and $\mathrm{p}_{\beta}$ stand for state variable, and $\mathrm{a}_{\mathrm{u}}$ stands for input voltage.

\subsubsection{Small signal model of bidirectional Buck- \\ Boost circuit}

$$
\hat{x}=A \hat{x}+B \hat{a}+C \hat{s}
$$

thereinto

$$
\begin{aligned}
& \mathrm{A}=\left[\begin{array}{cc}
0 & -\frac{1-s_{0}}{Q} \\
\frac{1-s_{0}}{C} & -\frac{1}{R C}
\end{array}\right], \mathrm{B}=\left[\begin{array}{c}
\frac{s_{0}}{Q} \\
0
\end{array}\right] \mathrm{a}, \\
& \mathrm{C}=\left[\begin{array}{cc}
0 & \frac{1}{Q} \\
-\frac{1}{C} & 0
\end{array}\right] x_{0}+\left[\begin{array}{c}
\frac{1}{Q} \\
0
\end{array}\right] a_{0}
\end{aligned}
$$

Then the transfer function of $\hat{x}$ and $\hat{a}$ was obtained:

$$
(l I-A)^{-1} B=\left[\frac{\frac{C l+1 / R}{Q C l^{2}+Q / R \times l+\left(1-s_{0}\right)}}{\frac{1-s_{0}}{Q C l^{2}+Q / R \times l+\left(1-s_{0}\right)}}\right]
$$

The transfer function of $\hat{x}$ and $\mathrm{s}$ was:

$$
(l I-A)^{-1} B=\frac{\left[\begin{array}{cc}
1-s_{0} & (l C+1) / R \\
-l Q & 1-s_{0}
\end{array}\right] x_{0}+\left[\begin{array}{c}
\frac{1}{Q} \\
0
\end{array}\right] a_{0}}{Q C l^{2}+Q / R \times l+\left(1-s_{0}\right)^{2}}
$$

\section{The Design of Simulation Experiment}

\subsection{Design of bidirectional DC/DC converter}

The design of bidirectional DC/DC converter is shown in figure 5 .

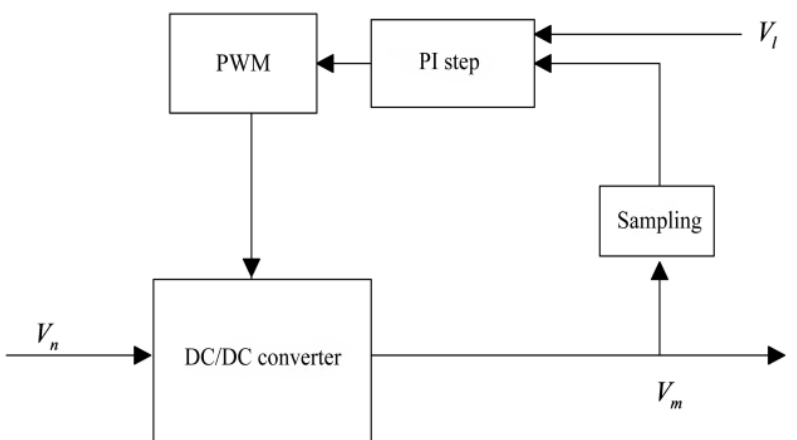

Figure 5: Design diagram of bidirectional $D C / D C$ converter 
The voltage which is output by bidirectional Buck-Boost circuit was compared with after the sampling step according to the ratio of 0.01 . The error signal of the two voltages was compared with triangular wave after being amplified by the PI step; then a square-wave pulse whose width changes along with the changes of output voltage was obtained. The square-wave pulse signal was connected with the switching tube on the main circuit as a driving signal. The other driving signal was obtained by connecting the square-wave pulse with NOT gate. Then two complementary pulse signals were obtained, which could realize the complementary breakover of the switching tube.

\subsection{The closed-loop step of bidirectional DC/DC converter}

Before experiment, different steps in closed loop of the system should be realized. The schematic diagram is as follows.

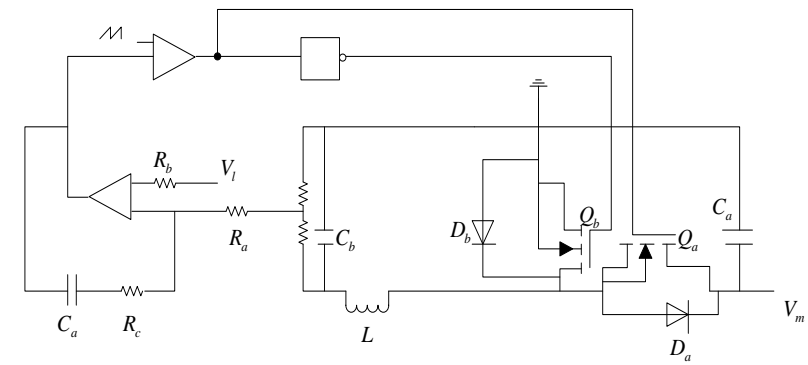

Figure 6: The schematic diagram of the closed loop of bi-directional DC/DC converter

The sampling step was realized by Voltage Controlled Voltage Source (VCVS). The compensation step was completed by PI regulator. The step of pulse width regulation was completed by SG3525 chip.

\subsection{The design of closed-loop regulator}

The closed-loop control of a DC/DC converter includes current control mode and voltage control mode [19]. As to current control mode, the following performance, stability and portability are poor and current and the power of converter cannot be controlled, which is not beneficial to the parallel connection of converter. This study investigated bidirectional DC/DC converter by means of industrial design. Determination of regulator parameters and requirements on stability and accuracy should be paid attention to in the design of regulators using industrial design method. The expression of open-loop transfer function of the control system was:

$$
W(l)=\frac{Z \prod_{\lambda=1}^{\rho}\left(\sigma_{\lambda} l+1\right)}{l^{r} \prod_{\gamma=1}^{\rho=r}\left(\kappa_{\gamma} l+1\right)} \quad \vartheta \geq \rho
$$

where $\mathrm{Z}$ stands for open-loop gain, $\sigma_{\lambda}$ and $\mathrm{k}_{\mathrm{y}}$ stand for constants, and $r$ stands for the multiple number of pole on the origin of coordinate $(r=1,2,3 \ldots$, corresponding to type I, II, III...). Type I and II systems were used. Before design, the characteristics of the two types of systems should be known. Type I system had poor following performance, small overshoot and weak anti-interference capacity, while type II system is featured by large overshoot, good following performance and anti-interference capacity.

\subsection{Simulation experiment of bidirectional DC/DC converter}

The mathematical model aforementioned was established in saber simulation software. Modular design was adopted. The circuits included power supply circuit, bidirectional DC/DC converter circuit, VCVS circuit, PI compensator circuit, peripheral circuit, circuit generated by driving signal and working mode switching circuit.

After modeling, the parameters were set: power: $12 \mathrm{KW}$, input voltage: $360 \mathrm{~V} \sim 540 \mathrm{~V}$, and output voltage: $240 \mathrm{~V}$. Resistive load was used. The switching frequency was $20 \mathrm{kHz}$, filter inductance was $1.3 \mathrm{mH}$, and filter capacitor was 500 uf.

Using the simulation model designed above, bidirectional DC/DC was simulated under different control modes. The flow direction of energy was changed by opening and closing the voltage switch, When the switch is closed, the converter was at BUCK mode; when the switch is open, it was BOOST mode. The model at BUCK mode, BOOST mode and the switching between the two modes and the designed closed-loop regulator were tested.

\section{Simulation Results}

\subsection{Simulation results at BUCK mode}

As shown in figure 7 , when the bidirectional DC/DC system operated at BUCK mode, the inductive current flew forward continuously. Therefore, the energy in the system flew from $V_{a}$ to $V_{b}$. The average value of voltage was $240.06 \mathrm{~V}$, the average value of current was $45.637 \mathrm{~A}$, and the ripple wave of inductive current was $5 \mathrm{~A}$. 
It could be noted that the data obtained in the experiment was basically same with the parameter given in the preceding text, satisfying the design requirements.

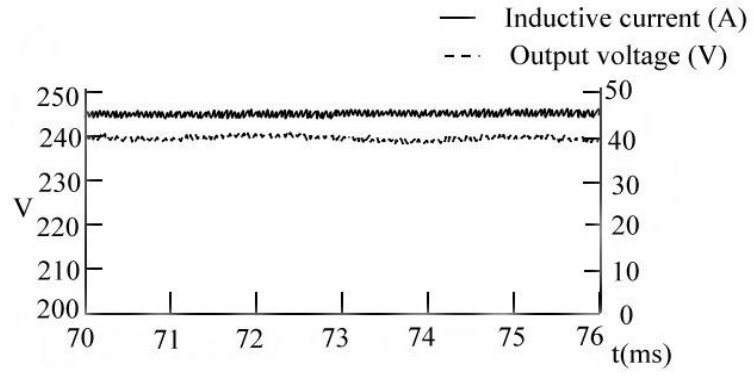

Figure 7: The waveforms of the output voltage and inductive current at BUCK mode

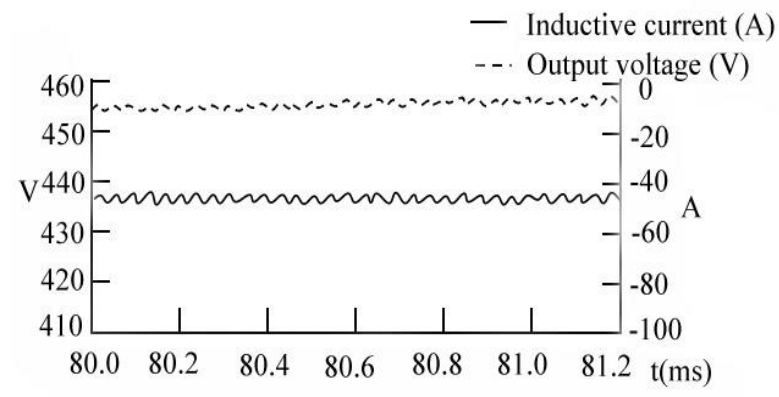

Figure 8: The waveforms of the output voltage and inductive current at BOOST mode

As shown in figure 8, when the system operated in BOOST mode, the inductive current flew in reverse direction continuously. Therefore, the energy in the system flew from $\mathrm{V}_{\mathrm{b}}$ to $\mathrm{V}_{\mathrm{a}}$.

The comparison of the simulation results of the inductive current in figure 7 and 8 suggested the same value but the opposite direction. In the simulation results, the average value of voltage was $455.25 \mathrm{~V}$, the average value of current was $48.139 \mathrm{~A}$, and the ripple wave of the inductive current was $5 \mathrm{~A}$. It could be noted that the data obtained in the experiment was basically same with the parameter given in the preceding text, satisfying the design requirements.

\subsection{Simulation results at the switching of the two modes}

Before the simulation experiment, four switches were designed for controlling BUCK source, BUCK load, BOOST source and BOOST load. The switching between BUCK mode and BOOST mode was realized through the complementary breakover of BUCK source, BUCK load, BOOST source and BOOST load. The simulation results are shown in figure 9.

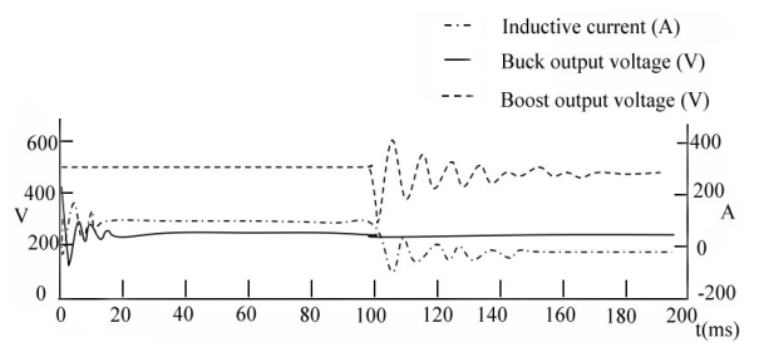

Figure 9: The waveforms of the output voltage and inductive current at the condition of bidirectional work

During bidirectional work, the current before 100 ms was forward current at BUCK mode, and the current after $100 \mathrm{~ms}$ was reverse current at BOOST mode. In the process of mode conversion, the inductive current transformed from positive direction to negative direction, realizing the bidirectional flow of energy.

\subsection{Simulation of current protection of regulator}

Whether the regulator protected the current passing through should be further simulated. The time was set as $0.25 \mathrm{~s}$; load resistance was as $6.77 \Omega$, but turned to be the original value at $0.3 \mathrm{~s}$. Results are shown in figure 10 .

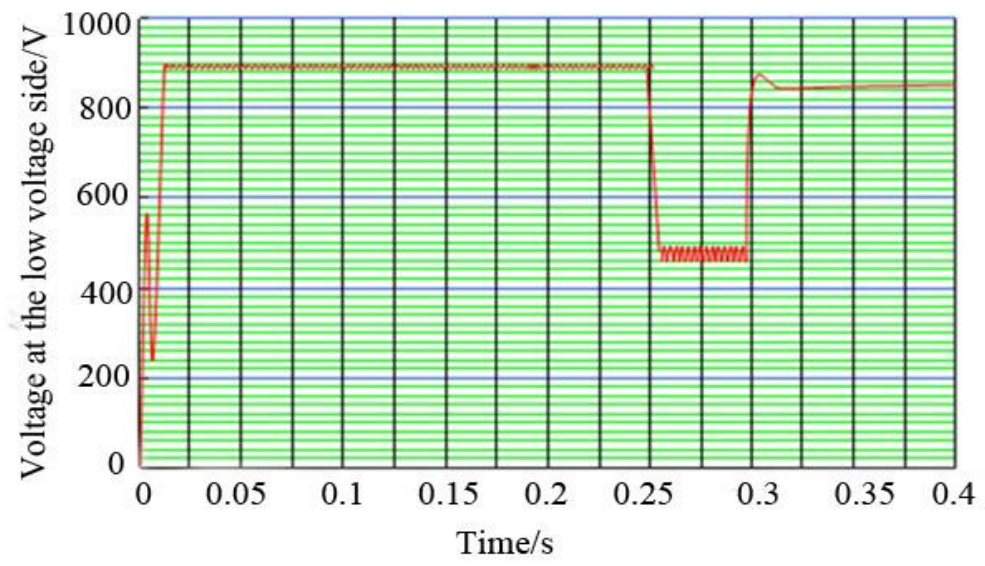

Figure 10: Changes of load voltage 


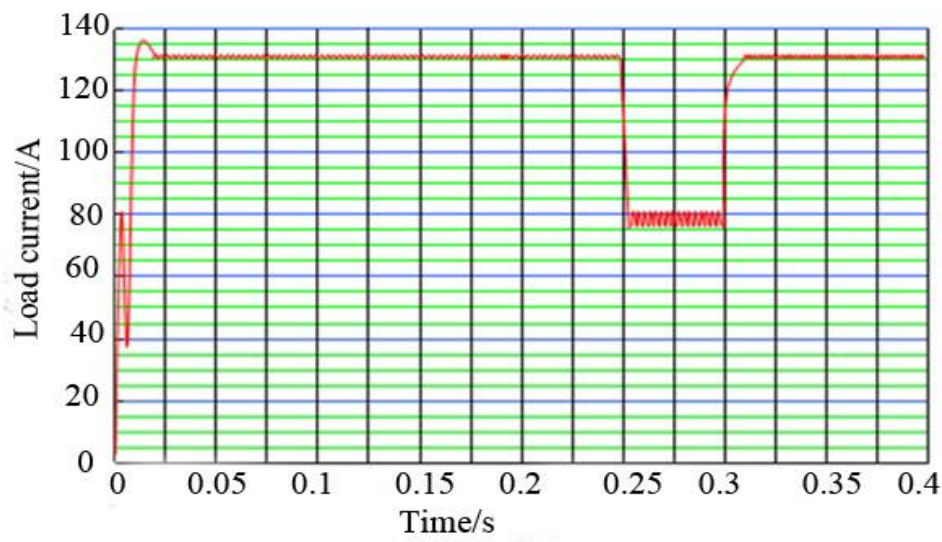

Figure 11: Changes of load current

In general condition, current would increase by 2 times if there was no protection from regulators, which could cause severe damages to regulators and equipment. As shown in figure 10 and 11, when the resistance turned to be half of the original value, the regulator would reduce voltage and current to half of the original values. Thus it could be concluded that, the regulator could protect the device.

\section{Discussion and conclusion}

Currently, studies on front-end bidirectional DC/DC converter mainly focus on isolated high-frequency DC/DC converter which is usually used in the reduction of high input voltage, but concern little about the transformation from high voltage to low voltage and from low voltage to high voltage. In real life, low-voltage and high-current power system is needed in many occasions. Xiong YS et al. [20] proposed a maximum power point tracing method for photovoltaic power generation system. Using this method, the working point was adjusted to the position around the maximum power point. Thus every module needs precise setting. The first application of bidirectional DC/DC converter in battery charger which aims to improve the power density and overall efficiency of energy flow has been extensively concerned [21]. With the constant deepening of studies, multiple types of topological structures have been proposed and the controlling methods become more and more accurate. By selecting Buck-Boost DC/DC converter suitable for large and medium-sized power, this study figured out small signal transfer function through modeling. Based on topological structure, bidirectional BuckBoost DC/DC converter was simulated. The simulation experiment suggested that the bidirectional DC/DC system could satisfy the bidirectional flow of energy and the designed regulator could protect the device. In this study, the controlling step of voltage and current of the bidirectional DC/DC converter was designed; however, the research was not comprehensive and the other parts need to be investigated. In conclusion, the design of bidirectional DC/DC converter has certain effectiveness and operability.

\section{Acknowledgement}

This work was supported by the D class Six Talent Peak Project in Jiangsu - the development of gridconnected inverter in distributed photovoltaic power generation system (Program No.: 2015-XNY017).

\section{References:}

[1] Zheng, Q. L. New development of power electronics technology for green energy technology. High Power Converter Technology, 2010 (1): 10-14.

[2] Romanian Review Precision Mechanics, Optics and Mechatronics. METHODS FOR REACTIVE POWER COMPENSATION IN PHOTOVOLTAIC PARKS. PhD. Student Eng. Cristian DIVOIU, Prof. PhD Eng. Gheorghe I. Gheorghe. Romanian Review Precision Mechanics, Optics \& Mechatronics nr.48 / 2015.273-275.

[3] Tunlasakun K. Vortex86sx microprocessor based islanding detection for photovoltaic grid connected inverter. World Academy of Science Engineering \& Technology, 2010(64): 345.

[4] Yang, L., Wang, S. T., Zhang, J. K. Double stage photovoltaic grid connected converter control strategy. Renewable Energy, 2014, 32 (11): 16201626.

[5] Gu, J. Y., Wu, H. F., Chen, G. C., et al. Research on photovoltaic grid-connected inverter based on soft-switching interleaved flyback converter// Industrial Electronics and Applications. IEEE, 2010:1209-1214.

[6] Guo, K. C., Gou, X. P., Xiao, X. Design of a photovoltaic inverter boost DC/DC converter based on full bridge LLC resonant converter. Electronic Design Engineering, 2015 (17): 118120. 
[7] Zhu, J. P., Zhou, J. P., et al. Simulation Research on DC power distribution network DC-DC converter converter. Guangdong Electric Power, 2015 (2): 20-24.

[8] Garcia, O., Zumel, P., Castro, A. D., et al. Automotive DC-DC bidirectional converter made with many interleaved buck stages. IEEE Transactions on Power Electronics, 2006, 21(3):578-586.

[9] Jovcic, D. Bidirectional, high-Power DC Transformer. IEEE Transactions on Power Delivery, 2009, 24(4):2276-2283.

[10] Bu, S. P., Cheng, L., Zhao, Z. A soft-switching halfbridge DC-DC converter and realization of its controlling method. Electrical Measurement \& Instrumentation, 2013 (3): 113-116.

[11] Devaraju, B., Ramasubramanian, J. An enhanced cascaded topology of non-isolated bidirectional DC-DC converter with switched coupled inductor. International Review on Modelling \& Simulations, 2013, 6(5):1371-1382.

[12] Ahmed, F., Kim, S. H., Cha, H., et al. Intermediate and light load efficiency improvement of a highpower density bidirectional DC-DC converter in hybrid electric vehicles with MR fluid gap inductor. International Power Electronics Conference, 2014:790-795.

[13] Yang, B., Li, W., Zhao, Y., et al. Design and Analysis of a Grid-Connected Photovoltaic Power System. IEEE Transactions on Power Electronics, 2010, 25(4):992-1000.

[14] Shahparasti, M., Larijani, A. S., Fatemi, A., et al. Quasi Z-source inverter for photovoltaic system connected to single phase AC grid// Power Electronic \& Drive Systems \& Technologies Conference. 2010:456-460.
[15] Li, X., Liang, H., Geng, J. High-frequency isolated grid-connected PV inverter based on SPWPM// Transportation Electrification Asia-Pacific. IEEE, 2014:1-4.

[16] Yousofidarmian, S., Barakati, S. M. TransformerLess Single-Phase Four-Level Inverter for PV System Applications. Journal of Power Electronics, 2014, 14(6):1233-1242.

[17] Wang, X., Zheng, J. H., Zhu, S. Z. The analysis of the transient characteristics of the PV system with hybrid energy storage system. Advanced Materials Research, 2012, 608-609:1058-1061.

[18] Wu, H., Xu, P., Hu, H., et al. Multiport Converters Based on Integration of Full-Bridge and Bidirectional DC-DC Topologies for Renewable Generation Systems. IEEE Transactions on Industrial Electronics, 2014, 61(2):856-869.

[19] Bryant, B., Kazimierczuk, M. K. Modeling the closed-current loop of PWM boost DC-DC converters operating in CCM with peak currentmode control. Circuits \& Systems I Regular Papers IEEE Transactions on, 2005, 52(11):24042412.

[20] Xiong, Y. S., Yu, L., Xu, J. M. Application of fixed voltage method combined with disturbance observer in photovoltaic maximum power point tracking control. Electric Power Automation Equipment, 2009, 29 (6): 85-88.

[21] Lu, Z., Zhao, J., Tseng, K. J., et al. Applying VRBESS in the DC micro-grid for green building electricity supply: Constructive suggestions to improve the overall energy efficiency// IEEE, International Conference on Power Electronics and Drive Systems. IEEE, 2013:130-135. 